
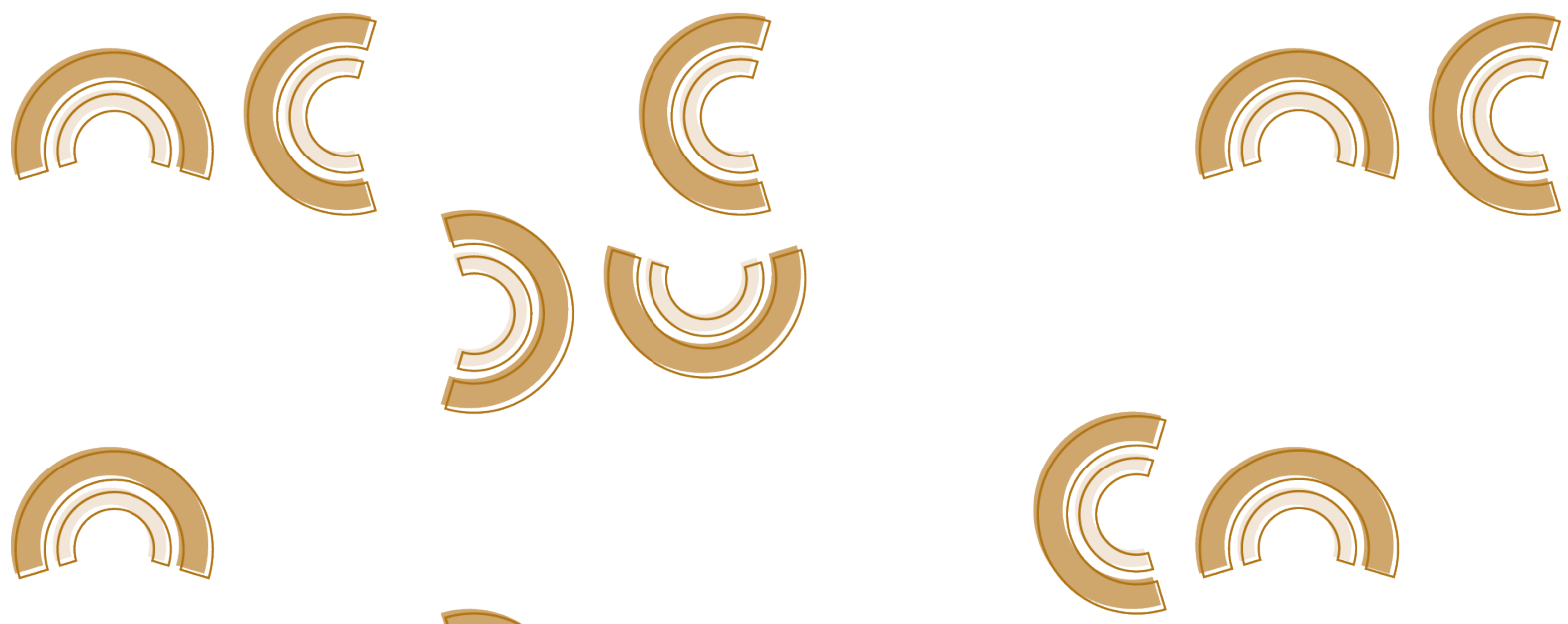

DOSSIÊ COMPOSIÇÃO,

DRAMATURGIA E PERFORMANCE

NA MÚSICA-TEATRO PÓS-1960

REFLEXÕES EM TORNO DO TEATRO-

MÚSICA DE CONSTANÇA CAPDEVILLE

REFLECTIONS ON CONSTANÇA

CAPDEVILLE'S MUSIC-THEATRE

\title{
Filipa Magalhães
}

CESEM, Centro de Estudos de Sociologia e Estética

Musical - NOVA FCSH

E-mail: filipa.magalhaes@campus.fcsh.unl.pt

DOI: https://doi.org/10.26512/dramaturgias.voi11.27385 


\section{RESUMO}

Constança Capdeville é a maior representante do teatro-música em Portugal. As suas composições vão além do musical, incluindo recursos extramusicais, como adereços, luzes, imagens, elementos teatrais e gravações em fita magnética. Esses recursos foram introduzidos nas suas obras, seja para estabelecer ambientes, estados emocionais ou para definir espaços. As obras de teatro-música de Capdeville, apesar de seu sucesso, também suscitaram reações controversas no público. Na perspetiva da compositora, a ópera e o concerto tradicional tinham terminado e, portanto, o conceito do palco deveria ser repensado. Capdeville referiu que, muitas vezes, teve que resolver esse problema criando os seus próprios palcos. Neste artigo, discutiremos o conceito de teatro-música no contexto da música contemporânea portuguesa e as suas influências nas composições de Capdeville.

Palavras-chave: Constança Capdeville. Teatro-música. Música contemporânea portuguesa. Performance. 


\begin{abstract}
Constança Capdeville is the greatest representative of music-theatre in Portugal. Her compositions extend beyond the musical by including extramusical features such as props, lights, images, theatrical elements, and magnetic tape recordings. These features were deployed in her works whether to establish environments, emotional states or to define spaces. Capdeville's music-theatre works, despite their success, also caused controversial reactions in the public. From her perspective, Opera and the traditional concert had finished and hence the concept of the stage required rethinking. Capdeville stated that often had to deal with this problem by creating her own stages. In this paper, it is discussed the concept of music-theatre within the context of Portuguese contemporary music and its influences over Capdeville's compositions.
\end{abstract}

Keywords: Constança Capdeville. Music-theatre. Portuguese contemporary music. Performance. 


\section{NOTA SOBRE CONSTANÇA CAPDEVILLE}

Constança Capdeville foi uma figura ilustre do panorama musical português, nomeadamente a partir do terceiro quartel do século XX. A compositora nasceu em Barcelona em 1937, local onde iniciou o seu percurso musical. Em 1951 chegou a Portugal com a sua família na sequência dos tumultos da Guerra Civil Espanhola dando continuidade à sua carreira musical, mas deixou-nos cedo, em 1992, com apenas 54 anos. Em Lisboa ingressou no Conservatório Nacional e estudou com os professores Lourenço Varela Cid (piano), Santiago Kastner (musicologia) e Jorge Croner de Vasconcelos (composição). Os ensinamentos e a forte personalidade deste último professor deixaram em Capdeville marcas profundas, que perduraram até ao fim da sua vida.

As principais atividades de Constança Capdeville repartiam-se entre a criação musical, o ensino e a interpretação (piano e percussão).

Em 1969 a sua carreira teve um impulso determinante com a encomenda da obra Diferenças sobre um intervalo ${ }^{1}$ por Maria Madalena de Azeredo Perdigão. ${ }^{2}$ Esta obra denotava já uma linguagem musical muito particular.

1 Primeira audição pela Orquestra Gulbenkian, no XIII Festival de Música Gulbenkian.

2 Diretora do Serviço de Música da Fundação Calouste Gulbenkian durante dezassete anos (entre 1958 e 1974). Posteriormente criou e dirigiu o Serviço ACARTE, de 1984 a 1989. Maria Madalena de Azeredo Perdigão foi uma figura de destaque na carreira de Constança Capdeville, tendo impulsionado e apoiado muitas das performances da compositora. 
Capdeville interessou-se também pela investigação musicológica, tendo colaborado entre 1964 e 1971 com a Comissão de Musicologia da Fundação Calouste Gulbenkian, com a Biblioteca Nacional de Portugal e com a Biblioteca da Ajuda. Participou na série televisiva "Binário" como compositora, diretora musical e autora de guiões. Cooperou com o Ballet Gulbenkian e com a Companhia Nacional de Bailado, compondo obras originais para coreografias de Vasco Wallenkamp, Olga Roriz e Carlos Trincheiras. e com o encenador Ricardo Pais no espetáculo Só Longe Daqui. A compositora colaborou ainda em peças de alguns dos encenadores mais importantes em Portugal, nomeadamente: Quinze rolos de moedas de prata (1979) de Mário Barradas; Molly Bloom (1981) de Carlos Quevêdo; A casa de Bernarda Alba (1983), Filhos de um Deus menor (1984) e Pílades (1985) encomendadas por Mário Feliciano; Muito barulho por nada (1990) encomendada por Luís Miguel Cintra, colaboração na composição do Miso Ensemble (SERRÃO 2010:238).

Das principais obras compostas por Capdeville destacam-se: Momento I (1970-71); Libera Me (1979), versão de concerto; Mise-en-Requiem (1979); In somno pacis (1980) para piano, oboé, viola de arco e contrabaixo; ...Vocem meam (1985) para voz solo; Amen para uma ausência (1986) versão para contrabaixo solo; Amen para uma ausência (1987), versão para viola, oboé, piano e contrabaixo; Border Line (1988) para saxofone solo; Di lontano fa specchio il mare (1989), à memória de Joly Braga Santos, para conjunto instrumental ad libitum; música para bailado: Libera Me (1977); Dimitriana, Lúdica, As Troianas (1985); música para filmes: Cerromaior (1980) realização de Luís Filipe Rocha; Solo de Violino (1990) realizado por Monique Rutler; obras de teatro-música: Esboços para um Stabat Mater (1981), Don't Juan (1985), Memoriae quasi una fantasia II (1986), Depois da Valsa (1987), FE...DE...RI...CO... (1987), The Cage (1988), Pero no la luna (1989), Wom Wom Cat(h)y (1990) em memória de Cathy Berberian. Constança Capdeville tinha uma necessidade incessante na procura de novas experiências e isso reflete-se indubitavelmente nas suas obras. Essa multiplicidade de interesses é evidente na diversidade dos caminhos que trilhou, compondo obras para orquestra, música de câmara, instrumentos a solo, dança, teatro e cinema, e criando espetáculos cénico-musicais. Capdeville é a grande representante do teatro-música no contexto da música contemporânea portuguesa. Como a própria compositora refere numa entrevista, ${ }^{3}$ a grande viragem na sua carreira ocorre a partir da composição de Momento I (1070/71), obra que Capdeville considera como o seu Opus I, e que corresponde a uma rotura em relação às suas obras precedentes, sobretudo em termos da exploração de dois elementos fundamentais: o tempo e a pesquisa tímbrica. ${ }^{4}$
3 Constança Capdeville entrevistada por Miguel Azguime em 1990. Disponível em: https://www.rtp.pt/ play/p1390/e363596/musica-hoje (04.08.2019).

4 Informação incluída no programa

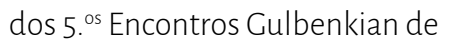
Música Contemporânea, concerto apresentado no dia 3 de junho de 1981, às 18:30, no Grande Auditório Gulbenkian (texto de Augusto M Seabra). 
Constança Capdeville propõe uma "nova atitude perante a noção de espetáculo através de uma abordagem interdisciplinar" (ROXO, 2010:309), criando uma linguagem cénico-musical vanguardista com características muito próprias, combinando concerto, teatro e dança, que juntamente com a exploração sonora, a música, a palavra, a luz, o gesto e o movimento constituem a performance. A componente cénico-visual ganhou cada vez mais importância nas suas composições, por isso Capdeville sentiu necessidade de criar em 1985 o grupo de teatro musical ColecViva, com o qual produziu diversos espetáculos. Estes, marcados por uma utilização criativa e esclarecida das tendências, novas técnicas e tecnologias da época, foram regularmente apresentados em festivais e encontros, tanto nacionais, como internacionais.

A compositora marcou de uma forma indelével a música portuguesa de vanguarda deixando em legado um conjunto de obras diversificadas e profundamente inovadoras. A sua coleção encontra-se atualmente à guarda da Biblioteca Nacional de Portugal (BNP). Esta inclui partituras, guiões, notas da compositora, imagens, suportes de fita magnética e outros documentos adicionais.

\section{O PANORAMA MUSICAL PORTUGUÊS NO CONTEXTO PÓS-REVOLUÇÃO}

A Fundação Calouste Gulbenkian (FCG) organizou o seu primeiro festival de música em 1958, dando oportunidade ao público português de ouvir alguns dos mais importantes compositores europeus daquela altura. A produção da década de 1960 foi marcante pois além de suscitar a consciencialização e a compreensão do público, também incentivou a procura de novas soluções musicais em Portugal. No entanto, "as maiores transformações sucederam após a Revolução de 25 de Abril de 1974, e foi apenas a partir deste período que a liberdade criativa se tornou efetiva"5 (PIRES ET AL., 2018:2). É precisamente nesta época e neste contexto que a Fundação Calouste Gulbenkian lança os Encontros Gulbenkian de Música Contemporânea (EGMC). Estes decorreram entre 1977 e 1992. A mesma fundação, em 1987, concebeu também os Encontros ACARTE (Serviço de Animação, Criação Artística e Educação pela Arte), um festival anual cujo intuito era apresentar o Novo Teatro/Dança da Europa (VIEIRA, 2016:3).

Os EGMC tiveram um enorme impacto na vida cultural, musical e artística portuguesa no final do século xx. Para além de proporcionarem novas oportunidades ao público português sendo apresentadas, como referido, inúmeras obras dos principais compositores e intérpretes internacionais da época, os encontros permitiram também a troca de conhecimento mútua entre compositores, músicos e artistas portugueses, assim como entre estes e figuras internacionais da cena musical contemporânea. Constança Capdeville absor-
5 "[...] the major transformations happened only after the April 25th Revolution, in 1974 that achieved real creative liberty [...]" (PIRES ET AL. 2018:2) Nossa tradução. 
veu os estímulos proporcionados por este tipo de iniciativas e foi nestes encontros que a compositora pôde estrear e apresentar muitas das suas obras (algumas delas encomendas da própria fundação), e ainda produzir os seus espetáculos de teatro-música.

\section{O TEATRO-MÚSICA DE CONSTANÇA CAPDEVILLE}

Constança Capdeville utilizou o conceito teatro-música em alternativa à expressão teatro musical, que nos anos 70 e 80 era mais conotada com o cabaré ou com a Broadway. O compositor António de Sousa Dias ${ }^{6}$ refere que a Capdeville dizia muitas vezes que: "tal como a Pina Bausch fazia teatro-dança, ela fazia teatro-música". ${ }^{7}$ A respeito da preferência de Capdeville pela denominação teatro-música Sousa Dias argumenta que, por um lado, "aproximava-a do tipo de trabalho levado a cabo por Pina Bausch, referido como teatro-dança, por outro, afastava-a de certo tipo de teatro musical mais próximo dos anos 60 e de certas formas de teatro do absurdo que não estavam necessariamente no centro das suas preocupações criativas." (SOUSA DIAS, 2019:3). No entanto, é importante realçar que Capdeville não se limitava a teatralizar o som. Para a compositora o som era um elemento fulcral, era este que trazia o gesto, não o gesto que criava uma roupagem. O contrabaixista Alejandro Erlich-Oliva ${ }^{8}$ explica que Capdeville explorava este instrumento musical de uma forma subversiva. Oliva comentou que, na obra Amen para uma ausência (1986), versão para contrabaixo solo que a compositora lhe dedicou

existe uma frase cromática que é uma loucura: o gesto imaginado pela compositora prescreve que certas notas sustentadas devem ser tocadas deslocando o contrabaixo (por meio de uma lenta extensão e flexão do braço esquerdo) em vez do movimento habitual do arco, usando o braço direito. Portanto, o arco está imóvel e é o contrabaixo que se desloca. Este procedimento, além do efeito visual insólito é uma subversão total da técnica normal de obtenção do som nos instrumentos de arco. ${ }^{9}$

Numa entrevista de 1982, a compositora referiu que o início da sua trajetória como compositora já revelava "uma preocupação com o tempo musical, a pesquisa tímbrica e a integração do movimento e da cor na obra musical." (RAMALHO, 1982:3). Capdeville considerava que não podia "isolar o movimento do músico daquilo que ele estava a executar [...]" (RAMALHO, 1982:5). A pesquisa sonora e tímbrica era um dos aspetos que mais a atraía, no entanto, a sua "maior dificuldade não era encontrar um novo som, mas sim a capacidade de poder transformá-lo em arte." (CoUTo \& VIDAL, 1972:9).
6 Colaborou como assistente de direção na parte técnica (e.g. montagem das fitas magnéticas e operador dos magnetofones nos espetáculos), e ainda como percussionista em diversas obras de Capdeville.

7 António de Sousa Dias, em entrevista presencial conduzida por Filipa Magalhães no dia 6 de janeiro de 2017.

8 Membro do ColecViva desde o início da sua fundação em 1985 até 1987.

9 Alejandro Erlich-Oliva, em entrevista presencial conduzida por Filipa Magalhães, no dia 12 dezembro de 2018. 
No que respeita à exploração sonora, Constança Capdeville foi profun10 Idem. damente influenciada pelo compositor John Cage, nomeadamente na utilização do piano preparado e do silêncio nas suas obras. Quanto à diversidade tímbrica, nas composições de Capdeville encontram-se algumas aproximações à obra de Edgar Varèse. Este último demonstrou ser possível tocar música eletrónica com instrumentos musicais convencionais (através do seu uso não-convencional). É nesse sentido que Capdeville se deixa imbuir pelas práticas de Varèse, utilizando os instrumentos musicais convencionais de forma atípica. Na opinião de Alejandro Erlich-Oliva, nas obras da compositora podem encontrar-se ainda influências, embora de maneira menos óbvia, do compositor Charles Ives principalmente no que concerne à noção de atonalidade. Nas composições de Capdeville, a atonalidade é produzida pela simultaneidade de músicas em diversos tons e não por meio da escrita atonal direta. ${ }^{10}$ Nas suas obras existem igualmente influxos do "teatro instrumental" de Mauricio Kagel, relativamente às atividades dos artistas em palco, mas não apenas. À semelhança do que acontece com Kagel, também para Capdeville não existem fronteiras no que respeita à atividade dos performers em palco. Nos seus espetáculos de teatro-música os performers eram atores, mimos, utilizavam a percussão, tocavam no corpo dos seus instrumentos e de outros objetos integrados no cenário ou interpretavam os seus instrumentos de forma pouco convencional ou em posições pouco convencionais. Por exemplo, em obras como Don't, Juan ou FE...DE...RI...CO..., os instrumentistas de cordas tocavam por vezes deitados ou ajoelhados. Kagel vem mudar o paradigma ao desenvolver novas formas de teatro musical, chamando a atenção para a teatralidade inerente à performance musical, noção que se reflete também no processo criativo de Constança Capdeville. Podemos dizer, portanto, que as obras de ambos contêm elementos teatrais explícitos e são intrinsecamente cénicas (os exemplos mais evidentes são as criações de Capdeville Momento I e Mise-en-Requiem).

Como suprarreferido, as composições de Constança Capdeville vão além do musical pois incluem recursos extramusicais tais como: adereços, luzes, imagens, elementos teatrais e gravações em fita magnética. Esses recursos foram inseridos nas suas obras tanto para estabelecer ambientes, como para determinar estados emocionais ou ainda para definir espaços. Pela não-convencionalidade que estes espetáculos apresentam, as obras de teatro-música de Capdeville tiveram sucesso, mas também provocaram reações controversas por parte do público. Na perspetiva da compositora, a ópera e o concerto tradicional tinham terminado e, portanto, era essencial repensar o conceito do palco. Na conceção dos seus espetáculos, Capdeville refere que um dos proble- 
mas que muitas vezes tinha que resolver era o do palco. A compositora nunca pôde, como gostaria, ter um palco rotativo, provavelmente por limitações financeiras e logísticas da época; quando trabalhou na Gulbenkian tentou adequar aos seus fins o palco "tradicional" da instituição, quando organizava espetáculos em sítios que não tinham um palco definido, era a compositora que criava o seu próprio palco (RAMALHO, 1982:5). Os espetáculos da compositora eram de curta duração, e quando havia mudanças de cena estas eram integradas no próprio espetáculo, logo não havia intervalos. A rotatividade era produzida pelos gestos dos performers (e.g. no espetáculo FE...DE...RI...CO... as sequências designadas por Palimpsestos são na verdade mudanças de cena). Também não existiam assistentes de palco, assim eram os próprios intérpretes que deslocavam os instrumentos e os adereços utilizados na performance.

Em Portugal no período dos anos 70/80, a noção que se tinha da performance estava mais ligada a fenómenos como "a performance art e sobretudo a situações de intervenção mais conotadas com o happening ou certas propostas de improvisação livre" (SOUSA DIAS, 2019:5), de facto este era só em parte o intuito do trabalho de Constança Capdeville. A compositora tinha uma abordagem ligeiramente diferente na forma como comunicava com os músicos, criando guiões em vez de partituras, tal como se faz nas peças de teatro ou no cinema. Capdeville antes dos seus espetáculos reunia-se pessoalmente com cada membro do grupo: o bailarino, o cantor, o pianista o contrabaixista, entre outros, trabalhava com eles individualmente e muitas das sugestões destes performers eram posteriormente integradas no resultado final, depois os vários membros reuniam-se todos e ensaiavam com mais frequência até à data do espetáculo.

Capdeville dava indicações aos performers, e a partir das mesmas estes criavam as suas próprias anotações porque o tipo de espetáculo aos quais estavam habituados eram diferentes, e porque os papéis que interpretavam nos espetáculos da compositora exigiam-lhes uma mudança de atitude relativamente à postura típica de um ator, músico ou bailarino em palco. Isso significava para cada um sair da própria zona de conforto para abraçar uma ideia mais abrangente daquilo que era a representação performativa (e.g. o contrabaixista Alejandro Erlich-Oliva por ser um músico profissional de orquestra criava os seus próprios guiões com as deixas principais, a fim de se orientar em cena e de se adaptar à componente teatral). Contudo, este tipo de práticas levanta problemas a nível da preservação das obras de Capdeville hoje em dia, pois tal como refere o pianista João Paulo Santos, numa entrevista à revista Glosas, Constança Capdeville escrevia para os amigos, que já sabiam o que significavam as indicações da partitura (sANTos, 2012:24). Uma parte 
dessas partituras eram criadas ou continham indicações específicas para cada músico e muitos dos materiais encontram-se atualmente na posse dos mesmos, outros materiais cujos artistas já faleceram estão mesmo perdidos, nesse sentido há materiais da coleção de Capdeville que estão dispersos e outros já se perderam.

A musicóloga Maria João Serrão refere que o teatro-música de Capdeville se caracteriza por: "adoptar as qualidades do som [...] como ponto de partida para a montagem do espetáculo, o guião substitui a 'partitura'; considerar os elementos da estrutura em níveis análogos, ou seja todos têm a mesma importância na obra; explorar a voz de formas não convencionais [...]; alargar a espacialização sonora e diversificar os espaços cénicos" (SERRÃO, 2006:22). A questão da espacialização é um aspeto muito importante na obra de Constança Capdeville; o acaso não existia e tanto a disposição dos músicos em palco, como a colocação dos instrumentos e da própria utilização da gravação eram bem definidas. A colocação dos performers ou dos instrumentos podia ter implicações em termos sonoros ou cénicos e visuais. Por exemplo, a colocação do piano era importante para que o efeito executado fosse mais facilmente visível pelo público, e porque o instrumento podia ser usado como adereço tal como acontece nos vários momentos em que o bailarino João Natividade se movimenta sobre a tampa do mesmo em obras como Don't, Juan (1985) ou FE...DE...RI...CO... (1987).

A dificuldade de desempenhar as obras de Capdeville, tanto pela dispersão de materiais, como pela complexidade de articulação dos vários elementos envolvidos nas mesmas, faz com que hoje em dia as suas obras raramente sejam interpretadas, há inclusive algumas que desde o desaparecimento da compositora nunca mais voltaram a ser apresentadas. Por essa razão, existem também muito poucas gravações comerciais disponíveis. A este respeito, a investigadora Maria João Serrão elaborou uma breve lista da discografia existente a qual apresentaremos no fim do texto (SERRÃO, 2012:39).

\section{A UTILIZAÇÃo DA COMPONENTE TECNOLÓGICA NA OBRA DE CONSTANÇA CAPDEVILLE}

A integração da tecnologia num palco era em meados dos anos 70 uma tarefa complexa tendo em conta os meios ao dispor. Nessa época Constança Capdeville utilizava como meios tecnológicos a gravação em fita magnética, a luz e os diapositivos. Os músicos, os atores, os bailarinos, os antigos alunos e outros que colaboraram diretamente com a compositora, reconhecem a importância do uso da tecnologia nas suas obras. Os sons gravados em fita magnética podiam ser entendidos como som de fundo, como uma personagem do espetáculo (como 
se se tratasse de um ator) ou como um elemento que realçava determinados aspetos da cena. Em termos de montagem, as gravações continham sons que resultavam de diferentes fontes: sons de instrumentos acústicos ou de objetos (i.e. gravações realizadas por vezes em casa da compositora com o auxílio dos intérpretes, sendo gravados: ataques executados em diversos instrumentos musicais, piano preparado, percussão, pacotes de açúcar que eram sacudidos e usados como maracas, entre outros); sons de textos falados, cantados, fonemas; alguns sons eram gravados na rua, como por exemplo, o comboio; e certos sons eram extraídos de outras gravações pré-existentes em fitas ou vinis).

Durante a performance, havia sempre necessidade de ter um técnico para operar a(s) fita(s) previamente preparadas pela compositora, contando com a colaboração dos seus técnicos. No que respeita à função da gravação em fita magnética nas obras de Capdeville, Alejandro Erlich-Oliva relatou que "os sons previamente gravados em certas obras de Constança Capdeville não funcionavam como um fator de orientação, não eram como um guia. As fitas magnéticas funcionavam como um elemento de amálgama, uma pasta mole que une peças duras". ${ }^{11}$ Esses sons serviam para conferir unidade à obra. António Sousa Dias referiu que a música de Capdeville não se inscreve inteiramente no género da música eletroacústica porque nem sempre a fita que Capdeville utilizava era usada como um instrumento (tal como sucede na definição de música eletroacústica). A fita magnética na obra de Capdeville era tão importante como a luz, o gesto e o movimento e não havia, portanto, uma hierarquia entre os vários elementos. Assim, são combinados diferentes elementos que interagem entre si e compõem o todo, sendo a fita um elemento de ligação entre vários outros.

Em relação à luz, pode dizer-se que esta atuava como um fator de orientação, enfatizando uma personagem, um objeto ou destacando sítios. Na opinião de Daniel Worm, "12 "a luz estabelecia ambientes ou estados de espírito, tal como sucedia na dança. Dada a ausência de cenografia, a luz acabava por definir espaços. E, claro, servia ainda a visibilidade do espetáculo." ${ }^{13}$ Orlando Worm $^{14}$ foi um dos primeiros desenhadores de luz com quem Constança Capdeville trabalhou, e numa entrevista conduzida por Ana Bigotte, este descreve momentos do seu percurso e ainda aspetos dos meios técnicos usados naquela época. Worm traça algumas diferenças relativamente ao trabalho de luz na dança e no teatro, referindo que o teatro estava subordinado a um tema ou a uma ação que se desenrolava e, nesse sentido, a iluminação deveria adequar-se a esse tema (BIGOTTE, 2010:47). Na dança era dada mais atenção à expressão corporal, logo a luz era mais abstrata e por isso era importante usar mais cor. Orlando Worm tinha também formação como cantor e isso torna-
11 Ibidem.

12 Colaborou com Capdeville como desenhador de luz nalgumas das suas últimas peças, nomeadamente Silêncio Depois (1990) e Take 91 (1991), ambas ligadas ao cinema.

13 Comunicação pessoal.

14 Cantor e desenhador de luz. 
va-o mais sensível à questão da música, portanto quando concebia a iluminação dava especial atenção à parte musical. "O iluminador procurava um ambiente adequado à música, aos figurinos, à própria coreografia: podendo esta ser rápida, lenta ou outra coisa, podendo ser muita gente, pouca gente, um solo" (BIGOTTE, 2010:48).

A projeção de diapositivos analógicos é outra componente tecnológica utilizada nas obras de Capdeville. Na maior parte dos casos, os performers não interagiam diretamente com este meio e segundo Alejandro Erlich-Oliva, os diapositivos passavam totalmente despercebidos aos intérpretes durante o espetáculo. Os diapositivos tinham o papel de comunicar com o público, sobressaindo determinados aspetos da cena, através, por exemplo, da apresentação de figuras (como a exibição de desenhos de Federico Garcia Lorca como as "Manos Cortadas" no espetáculo FE...DE...RI...CO...). Logo, o recurso a dispositivos influía diretamente na interação com o público e certamente esta relação quase direta com o público constituía uma escolha intencional da compositora. À semelhança do que acontece com os outros elementos, os diapositivos integravam o processo criativo sendo igualmente relevantes nas obras de Capdeville. No que concerne à interação dos vários elementos, como refere António de Sousa Dias a obra de Constança Capdeville é como um contraponto heterogéneo, em que pode haver uma correlação entre os materiais, mas não necessariamente uma coerência entre eles, isto verifica-se também no uso da componente tecnológica, por exemplo os diapositivos não têm uma relação com os intérpretes mas têm com o público, a gravação em fita magnética atua como uma espécie de amálgama entre os restantes elementos da obra e a luz é um fator de orientação na medida em que cria ambiências, mas estes elementos todos juntos são indissociáveis da obra porque a constituem.

\section{NOTA CONCLUSIVA}

Para concluir a nossa reflexão sobre o teatro-música da compositora Constança Capdeville, recorreremos a uma frase de Pedro Eiras, no seu texto alusivo às mulheres esquecidas. $O$ escritor refere que

[n] as obras de teatro musical de Constança Capdeville, músicos partilham o palco (e por vezes bastidores, frisas, camarotes) com actores, mimos, bailarinos, projecções de sequências de filmes. Em determinadas peças, o intérprete finge que toca o instrumento mas sem gerar qualquer som, o pianista folheia a partitura como quem procura algo (Mise-en-Requiem, 1979), um bailarino empurra um cavalo de madeira em cena ou faz bolas de sabão (Memoriæ, quasi una fantasia II, 1986), enquan- 
to o público entra na sala o afinador afina o piano - de cujo interior, mais tarde, sairá uma personagem (Don't, Juan, 1985), e ainda ocorrem jogos de bowling (...Para um Stabat Mater, 1988), bilhar, ténis, ping-pong, dados, ou um jogo de xadrez realizado sobre um tímpano (Double, 1982) (EIRAS, 2016:2-3)

Todos estes acontecimentos têm uma leitura simbólica e constroem livremente uma trama, exploram ainda efeitos de humor e de absurdo, desconstruindo qualquer trama dramática linear em concertos que se pretendem, em suma, desconcertantes. Eiras afirma ainda que "se estes gestos, movimentos e danças existem como espetáculo visual, o som resultante desses atos é parte imprescindível da composição musical (EIRAS, 2016:3).

Constança Capdeville abordou todos estes tipos de expressões, dentro de uma espécie de grande corrente em que a música é um polo central, não obstante, é precisamente a interação dos vários elementos presentes na sua obra que confere identidade à mesma, fazendo com que o legado desta compositora seja único no contexto da música contemporânea em Portugal.

\section{REFERÊNCIAS}

EIRAS, P. "Constança Capdeville: as vozes revisitadas." In: M.A. Silva \& M.G.

Besse (Eds.). Femmes Oubliées dans les Arts et les Lettres au Portugal

(XIXe-XXe siècles), 2016: 233-241. Paris: L' Harmattan.

PIRES, I., MAGALHÃES, F., \& NOGUEIRA, A. "Preservation and technological obsolescence: Portuguese contemporary musical heritage in perspective." In: Journal of New Music Research, 47.4(2018): 355-364. DOI: 10.1080/09298215.2018.1486433.

RAMALHO, M. “O sucesso para quê? Entrevista com Constança Cadpdeville." In: Grupo - Animação Cultural (Eds.). Informação Musical 6, pp. 3-5, 1982. COUTO, J. \& VIDAL, A. "Constança Capdeville: a silenciosa pesquisa do mundo sonoro." In: A. dos Reis Rodrigues (Dir.). Revista Flama, 29 de setembro de 1972, n. ${ }^{\circ}$ 1282, Ano XXIX, pp. 8-10, 1972.

ROXO, P. “ColecViva”. In: Salwa Castelo-Branco (Ed.) Enciclopédia da Música

em Portugal no Séc. XX, vol. 1 (A-C):309-310. Círculo de Leitores e Temas e Debates, 2010.

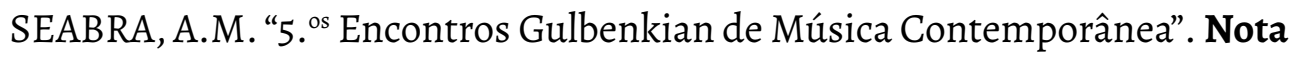
de Programa. Lisboa: Fundação Calouste Gulbenkian, pp. 77-89, 1981.

SANTOS, J.P. "Sete perguntas a João Paulo Santos." Glosas, 6, pp. 24-25, 2012. SERRÃO, M.J. "Breve apontamento sobre o teatro musical." Glosas, 6, pp. 37$39,2012$. 
SERRÃO, M.J. "CAPDEVILLE, Constança”. In: Salwa Castelo-Branco (Ed.), Enciclopédia da Música em Portugal no Século XX. Vol. I (A-C): 235-238. Lisboa: Círculo de Leitores/Temas e Debates Autores, 2010.

SERRÃO, M.J. Constança Capdeville Entre o Teatro e a Música. Lisboa: Edições

Colibri / Centro de Estudos de Sociologia e Estética Musical, 2006.

SOUSA DIAS, A. "ColecViva: 'teatro-música' como performance”. In: Cláudia Madeira, Hélia Marçal \& Fernando Matos Oliveira (Eds.). Práticas de Arquivo nas Artes Performativas. Coimbra: Imprensa da Universidade de Coimbra, (2019, no prelo).

VIEIRA, A. B. NO ALEPH, para um olhar sobre o Serviço ACARTE da Fundação

Calouste Gulbenkian entre 1984 e 1989. Tese de Doutoramento, Universidade

Nova de Lisboa, Faculdade de Ciências Sociais e Humanas, 2016. Link: http://hdl.handle.net/10362/19417.

VIEIRA, A.B. "Orlando Worm: 'Luz cinco vai! Som sete vai!'. Sinais de Cena N. ${ }^{\circ} 14$ (Dezembro 2010): 41-54. Link: https://revistas.rcaap.pt/sdc/issue/ view/770.

\section{DISCOGRAFIA}

Libera Me (na mesma edição de Amen para uma ausência e ... In somno Pacis (One for nothing)

1. ${ }^{a}$ ed. Portugalsom, 1991; $2 .^{a}$ ed. Strauss, 1994, SP 4030.

\section{Amen para uma ausência}

Versão para viola de arco, oboé, piano e contrabaixo, interpretado pelo Opus Ensemble gravação em Vinil, Ed. Discoteca Básica; CD, Ed. Portugalsom, 1. a ed. 1991; 2. ${ }^{a}$ ed. 1994.

\section{...In Somno Pacis (one for nothing)}

Viola de arco, oboé, piano e contrabaixo, interpretado pelo Opus Ensemble gravação em Vinil, Ed. Discoteca Básica, Lisboa; CD da Ed. Portugalsom, 1991; CD da Ed. Strauss, 1994.

Valse, valsa, vals: Keuschheits Waltz / La Prose du Transsibérien et de la Petite Jeanne de France / Amen para uma Ausência / ...Vocem Meam (Ucello) / Caixinha de Música / O Natal do Anjinho Dorminhoco.

Digital Recording, Miso Records MCD oo8; DDD, 1997.

\section{Variações sobre o Nome de Igor Stravinsky}

Órgão, por Monserrat Torrent. 
Prémio de Composição do Conservatório Nacional de Lisboa.

Gravação em Vinil, Ed. Egidsa, Lisboa.

\section{Sonata Concertante}

Trombone e piano

Ed. Alphonse Leduc, Paris: gravação em disco Ed. Educo, Lisboa.

\section{Momento I}

Flauta, guitarra percutida, percussão, voz e violino.

Ed. CD, EMI, Lisboa 1994.

\section{Di Lontan fa Specchio il Mare}

Conjunto instrumental "ad libitum";

Edição em CD, EMI, Lisboa 1994. 